\title{
Coacervation Process for Preparation of Encapsulate Lambda-Cyhalothrin
}

\author{
Hamzeh Saghafi ${ }^{* 1}$, Firoozeh Zarkesh ${ }^{2}$ and Hassan Kooshyar ${ }^{3}$
}

SJFST, 2021; 3(2): 1-5

1,2,3 Research and Development Laboratory of Samiran Company, Abbas Abad Industrial Town, Tehran, Iran.

\section{*Corresponding Author: \\ \h.saqafi@gmail.com}

Received: 05 January, 2021

Accepted: 13 April, 2021

Published: 25 April, 2021

\begin{abstract}
In the present study, a new type of an encapsulate pesticide was prepared by Coacervation method. Lambda-Cyhalothrin was encapsulated due to interaction between two oppositely charged materials, gelatin and gum Arabic as shell in a complex Coacevation process at the presence of $10 \mathrm{~mol}$ etoxylated nonyl phenol (NPE) which is a kind of a non-ionic emulsifier to enhance the homogenization of the product and size control. Spherical shape of capsules were scanned by Scanning Electron Microscopy (SEM) and optical microscope. The encapsulation efficiency was achieved $96 \%$ and analyzed by Gas chromatography equipped with FID detector (GC-FID). From the results of release study, 49, 63, 89\% of encapsulated materials were released from their shell after 15, 30,180 min respectively. The present study, applies a convenient and inexpensive method to introduce a pesticide, which can be exploited in public health field.
\end{abstract}

Keywords: Lambda-cyhalothrin, Coacervation, Encapsulation, Release study, Encapsulation efficiency

\section{Introduction}

Lambda-cyhalothrin belongs to a group of pesticides called pyrethroids which is registered by the U.S. Environmental Protection Agency (EPA) in 1988. It is offered as an alternative for Cyhalothrin about which is consisted of two diastereoisomeric pairs of isomers of Cyhalothrin. It is widely used as an effective insecticide in agriculture and public health domain such as hospitals and houses in different forms of formulations such as wettable powders, emulsion concentrates and capsule suspensions. Lambda-cyhalothrin and generally pyrethroids paralyze and extirpate insects by disrupting their nervous system $[1,2,3]$.

Microencapsulation is known as a process of which small droplets of a kind of core material in an emulsion bulk entrap into a shell. The shell or wall materials which cover the core materials can be chosen from polymers, polysaccharides, lipids or proteins. Core materials such as volatile materials, flavors, essential oils and pesticides are capsulated to become slow release or being released over a long period of time to take full advantage of them and also being protected against environmental influences such as light, oxygen and variety of other conditions $[4,5,6]$.

Abundant of methods have been widely carried out to protect the core materials during encapsulation process, which are divided into three main categories: chemical, physico-chemical and physico-mechanical methods among, which Coacervation technique that is a subcategory of physico-chemical method, have been using and developing since 1930 for many purposes [7]. Meticulously and simply, Coacervation will occur in circumstances as bellow:

a) Preparation of a homogenous emulsion of a core material in a solution of shell materials in water which are carrying opposite charges to have the maximum interaction between positive and negative charges to 
fold the core material by colliding with each other, for example gelatin with negative and positively charged acacia positively charged at the presence of an emulsifier.

b) Mild heating and agitation as well as $\mathrm{pH}$ adjustment, encapsulation takes place in this stage.

c) Cooling and adding cross linking materials such as formaldehyde or glutaraldehyde, the prepared capsules from stage 2 will be hardened by adding cross linking materials $[8,9,10,11]$.

The present study offers a slow-release insecticide product based on Coacervation method by gelatin/gum Arabic as shell materials and Lambda-cyhalothrin as core material, in which the core material releases over a long time, not only to increase the effectiveness, but also to enhance durability and stability.

\section{Experimental}

\section{Materials and devices}

Table 1

Chemical and physical properties of Lambda-cyhalothrin.

\begin{tabular}{llll}
\hline Chemical Name (IUPAC) & Structure & Molecular weight & Physical state \\
\hline $\begin{array}{l}\text { 3-(2-chloro-3,3,3- } \\
\text { trifluoro-1-propenyl) } \\
\text {-2,2-dimethyl-cyano } \\
\text { (3-phenoxyphenyl) } \\
\text { methyl cyclopropanecarboxylate }\end{array}$ & $449.85 \mathrm{gr} / \mathrm{mol}$ & $\begin{array}{c}\text { Off white } \\
\text { powder }\end{array}$ \\
\hline
\end{tabular}

\section{Preparation of capsules}

$5.0 \mathrm{gr}$ of gelatin powder and $5.0 \mathrm{gr}$ of gum Arabic were added into $100 \mathrm{~mL}$ distillated water separately under a mild agitation and heating until obtaining a homogenous solution and then were stored in a refrigerator overnight to complete the hydrolyzing process. $5.1 \mathrm{gr}$ of Lambda-cyhalothrin was dissolved in the minimum amount of Solveso $200 \mathrm{ND}$ and $2 \mathrm{gr}$ of NPE under a mild stirring and heating. For preparation of emulsion, the prepared solution of Lambdacyhalothrin was added into gum Arabic solution under a mild heating at $40^{\circ} \mathrm{C}$ and stirring for 30 minutes to break down the size of emulsified droplets of Lambdacyhalothrin. Furthermore, the solution of gelatin was poured into Lambda-cyhalothrin emulsion, slowly and dropwise continually over about $30 \mathrm{~min}$. $\mathrm{pH}$ was adjusted at 4 by adding acetic acid 20\% (W/V) afterwards. The obtained mixture was cooled down to below $10^{\circ} \mathrm{C}$ overnight in a refrigerator. In the end, the
A type gelatin and gum Arabic were prepared from chemical loacal market in Tehran, Kenon $10^{\circledR}$ or 10 mole etoxlytated nonyl phenol was from Kymiagaran Emrooz Industry. Solveso 200 ND was prepared from Hydro carbon Iran, Hydrochloric acid, Sodium hydroxide and glotaraldehide were purchased from Merck Company, Germany. Lambda-cyhalothrin was prepared from Gharda Company, India. Characteristic of Lambda-cyhalothrin is shown in table1. All solutions were prepared in distillated water. For investigation of release behavior of capsules, GC model Agilent 7890B and roller mixer model PLMA 001 Farzaneh Arman were applied. SEM model XL 30 Philips in Tarbiat Modares university and optical microscope model OLYMPUS CX23 Japan was used for scanning and detecting the shape of obtained capsules. The $\mathrm{pH}$ measurement was recorded by $\mathrm{pH}$ meter model AZ Taiwan. 


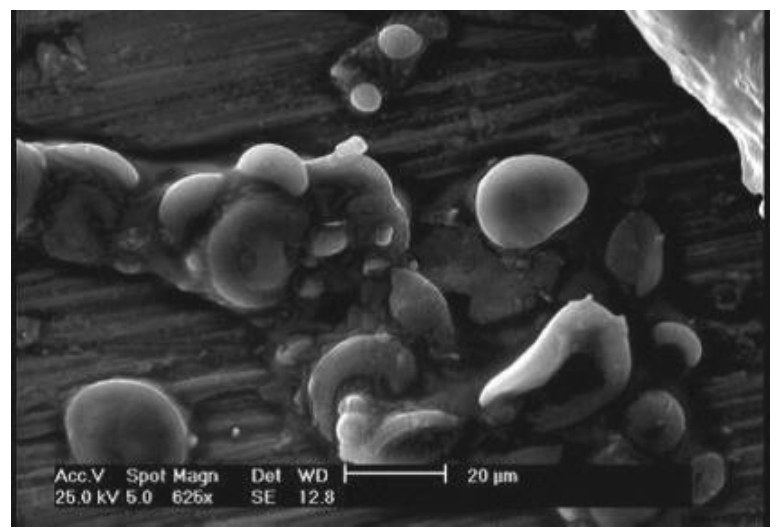

Figure 1. Spherical shape of Lambdacyhalothrin capsules by SEM

Optical microscope OLYMPUS CX23 was exploited to show the capsules shape as well. The result is shown in Figure 2.

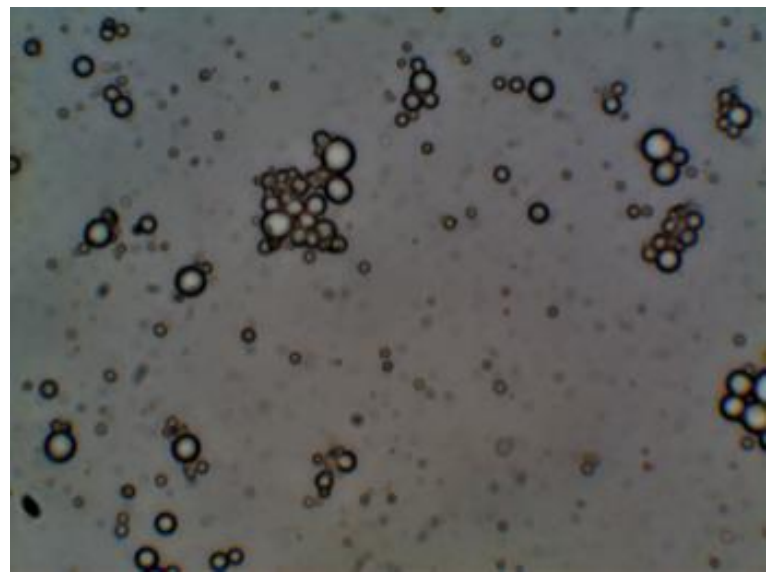

Figure 2. Image of Lambda-Cyhalothrin capsules by Optical microscope

\section{Microcapsule efficiency}

To measure the Microcapsule efficiency or encapsulation yield (the amount of capsulated LambdaCyhalothrin), 1 gr of the prepared sample (capsule solution) was transferred into a $60 \mathrm{~mL}$ glass tube, then 5-5.5 mL distillated water and $50 \mathrm{~mL}$-Hexan were added to the tube and the mixture was placed on a roller set at $70 \mathrm{RPM}$ for $5 \mathrm{~min}$. After 5 minutes $( \pm 10$ seconds) the bottle was removed from the roller and immediately a sample was taken from hexane layer for GC analysis under defined conditions as Table 2, below. Results were compared with analytical standard Lambda-Cyhalothrin. The amount of released LambdaCyhalothrin was measured as equation 1. The amount of non-capsulated Lambda-Cyhalothrin was obtained $4 \%$ which means $96 \%$ of Lambda-Cyhalothrin was successfully entrapped in the capsules (Interim specification WHO/IS/CS/463/2002).

GC chromatogram is shown in Figure 3. a and b, in which, (a) is the chromatogram of analytical standard of Lambda-Cyhalothrin and (b) is belonged to the amount of capsulated Lamda-Cyhalothrin.

Non-capsulated Lambda-Cyhalothrin $=\frac{\mathrm{RMP}}{\mathrm{R} / \mathrm{W}} \mathrm{g} / \mathrm{Kg}$

$\mathrm{R}=$ Total Lambda-Cyhalothrin peak ratio of released non-capsulated Lambda-Cyhalothrin

R'= Total Lambda-Cyhalothrin peak ratio of standard Lambda-Cyhalothrin

$\mathrm{M}=$ Mass of Lambda-Cyhalothrin Standard

$\mathrm{W}=$ Mass of the solution of encapsulated LambdaCyhalothrin sample

$\mathrm{P}=$ Purity of the Lambda-Cyhalothrin Standard

\section{Table 2}

GC-FID condition: Defined conditions for determination of the amount of released Lambda-Cyhalothrin in capsules.

\begin{tabular}{cccc}
\hline Inlet $\left({ }^{\circ} \mathbf{C}\right)$ & Oven $\left({ }^{\circ} \mathbf{C}\right)$ & Detector $\left({ }^{\circ} \mathbf{C}\right)$ & Carrier flow $\left(\mathbf{N}_{2}\right)(\mathbf{m L} / \mathbf{m i n})$ \\
\hline 250 & 280 & 320 & 0.9 \\
\hline
\end{tabular}




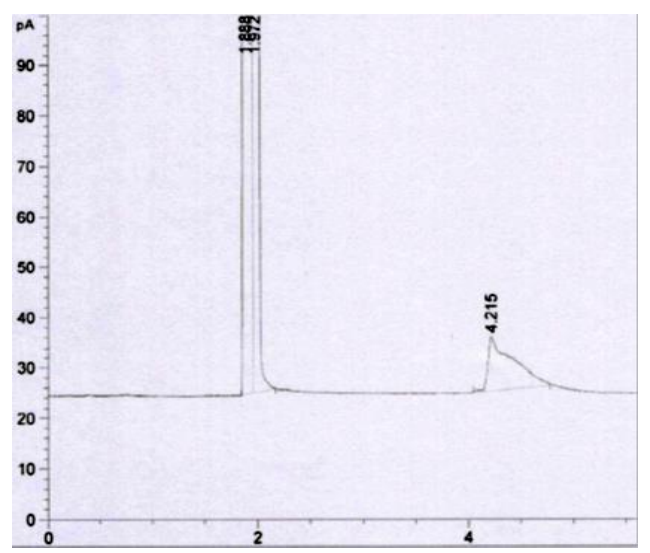

(a)

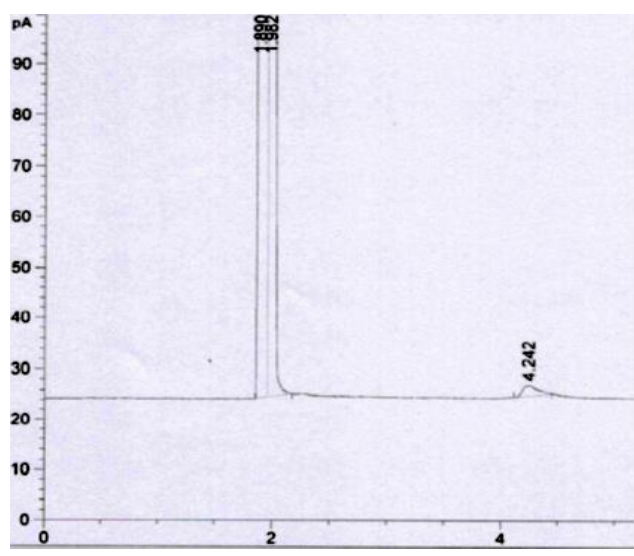

(b)

Figure 3. (a) chromatogram of analytical standard of Lambda-Cyhalothrin and (b) the amount of non-capsulated Lamda-Cyhalothrin

\section{Release study}

For investigation of releasing behavior of LambdaCyhalothrin in capsules, about $0.7-0.8 \mathrm{gr}$ of solution was weighted then 5-5.5 gr distillated water was added. The mixture was mixed with $90 \mathrm{~mL}$ of $\mathrm{n}$-Hexan and $10 \mathrm{~mL}$ ethanol in a $150 \mathrm{~mL}$ glass tube. The glass tube was sealed and put on a roller mixer at 70 RPM for 15, 30, 180 minutes. After aforementioned times the sample was taken from n-Hexan phase to analyze and calculate by the equation 1 which is given in section 3.2, by GC-FID [12].
Release of lambda-cyhalothrin from the capsules, determined by the given method, was included: at $15 \mathrm{~min}, 49 \%$ of that released at $180 \mathrm{~min}$; at $30 \mathrm{~min}, 63 \%$ of that released at $180 \mathrm{~min}$; and at $180 \mathrm{~min}$, a minimum of $89 \%$ of the total lambdacyhalothrin content determined according to the method.

The results from GC chromatogram is shown in Figure 4. are the amount of released Lamda-Cyhalothrin at $15,30,180 \mathrm{~min}$ respectively.

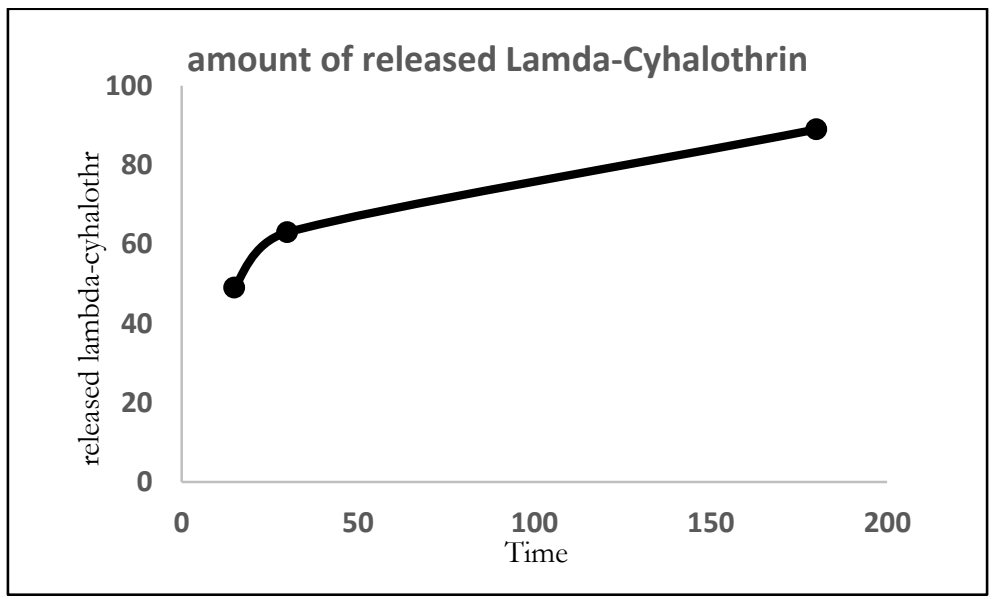

Figure 4. The amount of released Lamda-Cyhalothrin at 15,30, $180 \mathrm{~min}$

\section{Conclusion}

From the present reseach a simple and applicable method for encapsulation of Lambda-Cyhalothrin as a pyrothroid pesticide is offered which does not need for any special instrument to produce. From SEM pictures, the micrometric size of capsules were achieved by using an appropriate shell materials and also the time of mixing to have a homogeneous emulsion by Kenon
$10^{\circledR}$, before adding gelatin and complation of encapsulation process. It can be easily seen from Figure 4 and extracted data from the chromatoghraphs, the release behaviour of capsules shows a suitable adoption with the data, which is given in WHO standards. Encapsulation efficiency seems to be acceptable for this method as it can be resulted from Figure 3, more 
than $96 \%$ of Lambda-Cyhalothrin was encapsulated, because of having a strong interaction between oppositely charged gelatin and arabic gum as shell materials.

\section{Acknowledgments}

Authors wish to thank Mr. Hasan Kooshiar the CEO of Samiran Company for his directions, which encouraged us to research about this project.

\section{References}

1. U.S. Environmental Protection Agency (U.S. EPA). Lambda-cyhalothrin (General Fact-Sheet), 2001; http://npic.orst.edu/factsheets/1_cyhalogen.pdf

2. FAO specification and evaluation for plant protection products. Lambda-cyhalothrin specifications. 1999;

http://www.fao.org/fileadmin/templates/agphome/d ocuments/Pests_Pesticides/Specs/lambda13.pdf

3. Extension Toxicology Network. Lambda cyhalothrin, A Pesticide Information Project of Cooperative Extension Offices of Cornell University. 1995.

4. Yoon Y, Namjin B, Kinam P. Microencapsulation methods for delivery of protein drugs, biotechnol. Bioprocess Eng. 2001; 6: 213-230.

5. Ana PGR, Marcela GM, Josefina BC, Jorge EI, Fernando MB. Bio-insecticide Bacillus thuringiensis spores encapsulated with amaranth derivatized starches: studies on the propagation "in vitro'. Bioprocess Biosyst Eng. 2015; 38: 329-339.

6. Lang ZJ, Su YJ, WZ.-ying, Chen LP. Development, manufacture and application of Beta-Cypermethrin aqueous capsule suspension. J Forest Res. 2004; 5(3): 218-222.

7. Isabel MDM. Microencapsulation of thyme oil by coacervation: production, characterization and release evaluation, theses. Faculty of Engineering University of Porto. 2012.

8. Pratibha K, Kim D, Colin JB, Benu A. Microencapsulation of omega-3 fatty acids: A review of microencapsulation and characterization methods. $J$ Funct Food. 2015; 19: 868-881.

9. Chao P, Su-Qing Z, Jun Z, Gui-Ying H, Lan-Ying C, Feng-Yi Z. Chemical composition, antimicrobial property and microencapsulation of Mustard (Sinapis alba) seed essential oil by complex coacervation. Food Chem. 2014; 165: 560-568.

10. Sahar AM, Seid Mahdi J, Elham A, Danial D. Microencapsulation optimization of natural anthocyanins with maltodextrin, gum Arabic and gelatin. Int J Biol Macromol. 2016; 85: 379-385.

11. Firoozeh Z, Hamzeh S. Microencapsulation of Cypermethrin as a pyrethroid pesticide in agriculture. 3rd International Conference On Applied Research In Agriculture

Science. 2015; http:/ /www.civilica.com/Paper-AFPICONF03AFPICONF03_130.html

12. Interim specification WHO/IS/CS/463/2002. Lambda-Cyhalothrin Micro-Capsule Suspension. 2002; $1-7$.

\section{SJFST}

Copyright: (C) 2021 The Author(s); This is an open-access article distributed under the terms of the Creative Commons Attribution License (http://creativecommons.org/licenses/by/4.0), which permits unrestricted use, distribution, and reproduction in any medium, provided the original work is properly cited.

Citation: Saghafi H, Zarkesh F, Kooshyar H. Coacervation Process for Preparation of Encapsulate LambdaCyhalothrin. SJFST, 2021; 3(2): 1-5. 